\title{
醛酮的不对称硅氰化反应研究进展
}

\author{
傅 颖* 侯 博 赵兴玲 杜正银胡雨来 \\ (西北师范大学化学化工学院 兰州 730070)
}

\begin{abstract}
摘要 羰基化合物的不对称氰醇化反应是当前不对称催化领域里的一个研究热点. 具有光学活性的氰醇是有机合成的 重要中间体，通过官能团转化可以很容易制备出一些在天然产物和化学制药中具有重要意义的手性化合物，如 $\beta$-氨基 醇、 $\alpha$-氨基酸和 $\alpha$-羟基酸等. 目前, 不对称催化的三甲基氰硅烷与醛酮的加成反应作为手性㲵醇的主要化学合成方法受 到人们的广泛关注, 而反应体系中采用的手性配体与 Lewis 酸是控制这类反应的效能和立体选择性的关键, 因此, 主要 就三甲基氰硅烷和醛酮不对称加成反应中催化体系的发展作了一个简要的述评.
\end{abstract}

关键词 手性催化; 不对称硅氰化反应; 醛酮; 手性配体

\section{Progress on the Asymmetric Silylcyanation of Aldehydes and Ketones}

\author{
Fu, Ying* Hou, Bo Zhao, Xingling Du, Zhengyin Hu, Yulai \\ (College of Chemistry and Chemical Engineering, Northwest Normal University, Lanzhou 730070)
}

\begin{abstract}
The asymmetric cyanation of carbonyl compounds occupies a hot research topic in current catalytic chemistry. Optically pure cyanohydrins are important synthetic intermediates which can be easily transformed into optically pure compounds, including $\beta$-aminoalcohols, $\alpha$-amino acids and $\alpha$-hydroxy acids, thus exihibits fundermental utility in many natural products and chemical pharmacy synthesis. Presently, the asymmetric silylcyanation of trimethylsilyl cyanide with aldehydes and ketones represents a main approach for optically pure cyanohydrin synthesis. The complex of chiral ligand and Lewis acid is the key element that determines the efficiency and controls the stereochemisty of these reactions. This review briefly summarizes the development of asymmetric catalysis empolyed in the chiral cyanohydation of aldehydes and ketones using trimethylsilyl cyanide as the cyanating agent.
\end{abstract}

Keywords chiral catalysis; asymmetric silylcyanation; aldehyde and ketone; chiral ligand

羰基化合物的不对称硅氧化反应一直以来受到了 有机化学工作者们的广泛关注. 具有光学活性的氰醇是 重要的有机合成中间体, 其通过官能团转化可以很容易 制备一些在天然产物和化学制药合成上具有重要意义 的手性化合物，如 $\beta$-氨基醇、 $\alpha$-氨基酸和 $\alpha$-差基酸等 ${ }^{[1]}$. 合成氧醇的方法有许多, 然而这些方法合成的产物都是 外消旋化的, 如果要得到光学活性的产物还必须进行拆 分. 因此, 为了克服这个难题人们发展了很多不对称合 成方法, 主要包括生物催化法和化学催化法. Chen 等 ${ }^{[2]}$ 已对生物催化合成手性氧醇的进展进行了简要述评, 而 三甲基氰硅烷与醛酮的不对称硅氰化反应作为化学合
成的主要方法同样也受到化学工作者们的广泛关注, 并 开发了许多催化体系. 在本综述中, 我们详述了此反应 中钛基、铝基、钒基等一些近些年出现的新型催化体系 的研究进展.

\section{1 醛的不对称硅氭化反应}

\section{1 硼基催化体系}

1986 年 Reetz 等 ${ }^{[3]}$ 率先报道了以手性路易斯酸硼杂 环化合物 1 或 2 为催化剂, 通过三甲基氰硅烷与异丁醛 在一 $78{ }^{\circ} \mathrm{C}$ 反应 $140 \mathrm{~h}$, 经水解顺利得到手性 2-差基- 4 甲基一戊腈，收率 $45 \% \sim 55 \%$ ，对映选择性 12\% 16\%.

\footnotetext{
*E-mail: fu_yingmail@126.com

Received May 28, 2015; revised June 29, 2015; published online August 17, 2015.

Project supported by the National Natural Science Foundation of China (Nos. 21262030, 20962017) and the Natural Science Foundation of Gansu Province (No. 1107RJZA263).

国家自然科学基金(Nos. 21262030, 20962017)和甘肃省自然科学基金(No. 1107RJZA263)资助项目.
} 
然而产物构型在当时没有被确定.<smiles>CO[B-]1(c2ccccc2)CCC[C@H]1c1ccccc1</smiles>

1<smiles>ClB1C(c2ccccc2)CCC1c1ccccc1</smiles>

2
2004 年 Corey 小组 ${ }^{[1 b]}$ 报道了在三苯基氧膦和催化 量(10 mol\%)的硼化合物 3 存在下, 以三甲基氰硅烷与醛 的化学合成方法合成了一系列手性氰醇硅醚, 收率高达 98\%, 对映选择性高达 $97 \%$. 无论是芳香醛还是脂肪醛 都能达到较优异的收率和对映选择性.

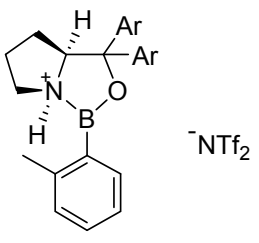

3

\section{2 钛基催化体系}

继 Reetz 的工作之后, 1987 年 Narasaka 小组 ${ }^{[4]}$ 首次 在 $4 \AA$ 分子篮和配体 4 的铁配合物作用下通过三甲基氰 硅烷与醛不对称加成顺利合成了手性氧醇, 收率高达 $89 \%$, 对映选择性高达 $96 \%$. 尽管配体 4 和钛的络合物 没有实现催化剂量的促进反应，但说明手性钛基路易斯 酸具有实现优异对映选择性合成氧醇的潜力.<smiles>CC1(c2ccccc2)OC(C(O)(c2ccccc2)c2ccccc2)C(C(O)(c2ccccc2)c2ccccc2)O1</smiles>

\section{4}

1990 年 Oguni 小组 ${ }^{[5]}$ 首次报道了以 L-( +)-酒石酸二 异丙酯(5)与四异丙醇钛等呈络合催化的三甲基氰硅烷 与芳香醛的反应. 研究发现, 在 $0{ }^{\circ} \mathrm{C}$ 二氯甲烷中加入 2 倍量异丙醇的最优反应条件下, 得到手性氰醇硅醚的对 映选择性可达 $91 \%$. 虽然作者用化学计量的手性路易斯 酸获得了较高的收率和 $e e$ 值, 但底物的官能团兼容差, 催化剂用量较多(20 mol\%).<smiles>CC(C)OC(=O)C(O)C(O)C(=O)OC(C)C</smiles>

5

之前已经发现一些环肽化合物能够催化氰化氢与 醛的不对称加成反应 ${ }^{[6]}$, 随后 Inoue 课题组 ${ }^{[7]}$ 制备了氨基 酸以及肽衍生席夫碱 $6 \sim 13$, 并测试以它们的钛配合物 为催化剂合成手性氰醇. 研究发现, 二肽衍生物比由单
一氨基酸衍生的席夫碱得到的结果更优异，并且其中一 些配合物在该反应中展现了良好的催化活性，如 Nap- $(S)$-Val- $(S)$-Trp-OMe (6) 的铁配合物得到产物 $e e$ 值 高达 $90 \%$.

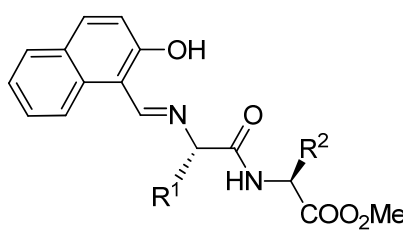

$6 \mathrm{R}^{1}=\mathrm{Me}_{2} \mathrm{CH}, \mathrm{R}^{2}=3$-indolyl $7 \mathrm{R}^{1}=\mathrm{Me}_{2} \mathrm{CH}, \mathrm{R}^{2}=\mathrm{CH}_{2} \mathrm{Ph}$ 8 enantiomer of 6 9 enantiomer of 7<smiles>COC(=O)[C@H](N=Cc1c(O)ccc2ccccc12)C(C)C</smiles>

11<smiles>CC(C)[C@H](NCc1ccccc1)C(=O)N=Cc1c(O)ccc2ccccc12</smiles><smiles>CC(C)C(N=Cc1c(O)cc(Br)cc1Br)C(=O)N1CCCCC1</smiles>

12<smiles>COC(=O)[C@H](Cc1ccccc1)NC(=O)[C@H](N=Cc1c(O)ccc2ccccc12)C(C)C</smiles>

Oguni 小组 ${ }^{[87}$ 将 $\beta$-氨基醇衍生物配体 $\mathbf{1 4} \sim \mathbf{2 5}$ 的钣配 合物成功地应用到苯甲醛的不对称硅氰化反应. 研究发 现, 配体 15 的钛配合物催化合成手性氧醇硅醚的对映 选择性最优 $(85 \% e e)$. Jiang 课题组 ${ }^{[9]}$ 也研究了具有类似 骨架的催化体系, 发现一些配体的钛配合物的催化性能 随温度降低而增强，如配体 26 和 27.<smiles>[R]c1cc([R])c(O)c(N=CC([R])([R])O)c1</smiles> 
<smiles>[R]c1cc([R])c(O)c(/C=N/C(c2ccccc2)c2ccccc2)c1</smiles>

$$
\begin{aligned}
26 R^{1} & =R^{2}=H \\
27 R^{1} & =R^{2}=t-B u
\end{aligned}
$$

Walsh 和 Somanathan 等 ${ }^{[10]}$ 报道了以顺式-1-氨基-2狮满醇及其他氨基醇衍生物为配体的催化体系. 通过将 配体 28 43 与 $20 \mathrm{~mol} \%$ 四异丙氧基钛络合催化三甲基 氧硅烷与苯甲醛的反应. 研究发现, 以配体 29 的钛配合 物为催化剂时，得到手性氮醇的对映选择性最优 $(85 \%$ $e e)$.

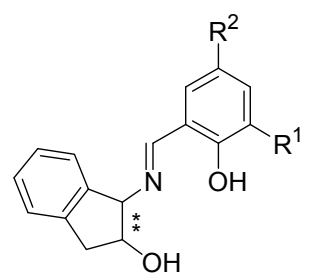

$$
\begin{aligned}
& 28 \mathrm{R}^{1}=t-\mathrm{Bu}, \mathrm{R}^{2}=t-\mathrm{Bu} \\
& 29 \mathrm{R}^{1}=t-\mathrm{Bu}, \mathrm{R}^{2}=\mathrm{H} \\
& 30 \mathrm{R}^{1}=t-\mathrm{Bu}, \mathrm{R}^{2}=\mathrm{CH}_{3} \\
& 31 \mathrm{R}^{1}=\mathrm{Adamantyl}, \mathrm{R}^{2}=\mathrm{Me} \\
& 32 \mathrm{R}^{1}=\mathrm{R}^{2}=\mathrm{CMe}_{2} \mathrm{Et} \\
& 33 \mathrm{R}^{1}=\mathrm{R}^{2}=\mathrm{CMe}_{2} \mathrm{Ph}
\end{aligned}
$$<smiles>[R]c1cc([R])c(O)c(/C=N/C([R])C([R])O)c1</smiles>

$$
\begin{aligned}
& 34 \mathrm{R}^{1}=\text { Adamantyl, } \mathrm{R}^{2}=\mathrm{Me}, \mathrm{R}^{3}=t-\mathrm{Bu}, \mathrm{R}^{4}=\mathrm{H} \\
& 35 \mathrm{R}^{1}=\mathrm{R}^{2}=\mathrm{CMe}_{2} E t, \mathrm{R}^{3}=t-\mathrm{Bu}, \mathrm{R}^{4}=\mathrm{H} \\
& 36 \mathrm{R}^{1}=\mathrm{R}^{2}=\mathrm{CMe}_{2} \mathrm{Ph}, \mathrm{R}^{3}=t-\mathrm{Bu}, \mathrm{R}^{4}=\mathrm{H} \\
& 37 \mathrm{R}^{1}=\text { Adamantyl, } \mathrm{R}^{2}=\mathrm{Me}, \mathrm{R}^{3}=\mathrm{Ph}, \mathrm{R}^{4}=\mathrm{H} \\
& 38 \mathrm{R}^{1}=\mathrm{R}^{2}=\mathrm{CMe}_{2} \mathrm{Et}, \mathrm{R}^{3}=\mathrm{Ph}, \mathrm{R}^{4}=\mathrm{H} \\
& 39 \mathrm{R}^{1}=\mathrm{R}^{2}=\mathrm{CMe}_{2} \mathrm{Ph}, \mathrm{R}^{3}=\mathrm{Ph}, \mathrm{R}^{4}=\mathrm{H} \\
& 40 \mathrm{R}^{1}=\mathrm{Adamantyl}^{2} \mathrm{R}^{2}=\mathrm{Me}, \mathrm{R}^{3}=\mathrm{R}^{4}=\mathrm{Ph} \\
& 41 \mathrm{R}^{1}=\mathrm{R}^{2}=\mathrm{CMe}_{2} \mathrm{Et}, \mathrm{R}^{3}=\mathrm{R}^{4}=\mathrm{Ph} \\
& 42 \mathrm{R}^{1}=\mathrm{R}^{2}=\mathrm{CMe}_{2} \mathrm{Ph}, \mathrm{R}^{3}=\mathrm{R}^{4}=\mathrm{Ph} \\
& 43 \mathrm{R}^{1}=\text { Adamantyl, } \mathrm{R}^{2}=\mathrm{Me}, \mathrm{R}^{3}=\mathrm{CHMe}, \mathrm{R}^{4}=\mathrm{H}
\end{aligned}
$$

由樟脑衍生物配体制备的手性催化剂也引起了化 学工作者们的兴趣. 2001 年 Tang 小组 ${ }^{[11]}$ 制备了樟脑衍 生物手性席夫碱配体 44 46 与四异丙醇钛络合的钛配 合物, 并成功应用到苯甲醛的不对称三甲基硅氰化反 应. 研究发现, 在最优条件下配体 $\mathbf{4 4}$ 的钛配合物催化合 成手性氰醇的对映选择性最优 $(66 \% e e)$.<smiles>[R]c1cc([R])c(O)c(/C=N/C2CCC(C)(C)C2/N=C/c2cc([R1])cc([R])c2O)c1</smiles>

$$
\begin{aligned}
& 44 \mathrm{R}^{1}=\mathrm{R}^{2}=\mathrm{H} \\
& 45 \mathrm{R}^{1}=\mathrm{R}^{2}=\mathrm{Cl} \\
& 46 \mathrm{R}^{1}=\mathrm{Me}, \mathrm{R}^{2}=t-\mathrm{Bu}
\end{aligned}
$$

2014 年 Ewelina 等 ${ }^{[12]}$ 也报道了以樟脑衍生物手性席 夫碱配体 47 49 的钛配合物作为催化剂, 通过三甲基 氧硅烷与醛在 $-20{ }^{\circ} \mathrm{C}$ 二氯甲烷中不对称加成顺利得到 手性氭醇硅醚，对映选择性 13\% 99\%. 研究发现，混 合的 $\mathrm{Ti}(\mathrm{O} i-\mathrm{Pr})_{4} / \mathbf{4 9}$ 产生了具有催化活性的 $\mathrm{Ti}(\mathrm{O} i-\mathrm{Pr})_{2}$ 和 无活性的 Ti, 它们的比例取决于起始混合物.

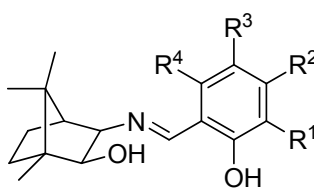

$$
\begin{aligned}
& 47 R^{1}=R^{2}=R^{3}=R^{4}=H \\
& 48 R^{1}=M e, R^{2}=R^{3}=R^{4}=H
\end{aligned}
$$$$
49 \mathrm{R}^{1}=i-\mathrm{Pr}, \mathrm{R}^{2}=\mathrm{R}^{3}=\mathrm{R}^{4}=\mathrm{H}
$$

2006 年 Moyano 等 ${ }^{[13]}$ 合成了一系列二茂铁衍生的 $C_{1}$ 对称性配体 $\mathbf{5 0} \sim \mathbf{5 7}$, 然后与四异丙醇钣络合并成功 应用到醛的不对称硅氧化反应. 研究发现, 配体 $\mathbf{5 3}$ 的钛 配合物在此反应中展现了良好的催化活性，收率可达 $91 \%$, 对映选择性可达 $86 \%$. 为了作对比, 他们用类似 非二茂体衍生物配体 $\mathbf{5 8}$ 在相同条件下得到产物的 $e e$ 仅 仅 $50 \%$ 。<smiles>[R]c1cc(O)c(/C=N/C2(C([R])([R7])O)c3ccccc3[R]2([H])c2ccccc2)cc1[R]</smiles>

$$
\begin{aligned}
& 50 R^{1}=R^{2}=R^{3}=H, R^{4}=R^{5}=M e \\
& 5_{1} R^{1}=t-B u, R^{2}=R^{3}=R^{4}=R^{5}=H \\
& 52 R^{1}=t-B u, R^{2}=R^{3}=R^{4}=H, R^{5}=M e \\
& 53 R^{1}=t-B u, R^{2}=H, R^{3}=M e, R^{4}=R^{5}=H \\
& 54 R^{1}=t-B u, R^{2}=R^{3}=H, R^{4}=R^{5}=M e \\
& 55 R^{1}=t-B u, R^{2}=R^{3}=R^{4}=H, R^{5}=P h \\
& 56 R^{1}=1 \text {-adamantyl, } R^{2}=M e, R^{3}=R^{4}=R^{5}=H \\
& 57 R^{1}=1 \text {-adamantyl, } R^{2}=R^{3}=M e, R^{4}=R^{5}=H
\end{aligned}
$$


<smiles>CC(C)(C)c1cccc(/C=N/C(CO)c2ccccc2)c1O</smiles>

58

Belokon 和 North 等 ${ }^{[14]}$ 发现在 $C_{1}$ 对称性 Salen 钛配 合物 59 62 催化下, 三甲基氰硅烷与醛反应也能顺利 得到手性氰醇硅醚, 产率 $60 \%$ 85\%, 对映选择性 $25 \% \sim 76 \%$.

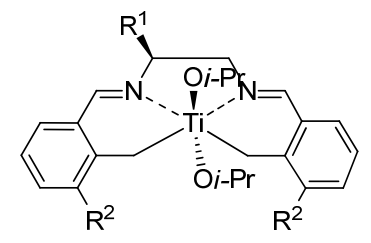

$$
\begin{aligned}
& 59 \mathrm{R}^{1}=\operatorname{MeS}\left(\mathrm{CH}_{2}\right)_{2}, \mathrm{R}^{2}=\mathrm{H} \\
& 60 \mathrm{R}^{1}=\operatorname{MeS}\left(\mathrm{CH}_{2}\right)_{2}, \mathrm{R}^{2}=t-\mathrm{Bu} \\
& 61 \mathrm{R}^{1}=n-\mathrm{Pr}, \mathrm{R}^{2}=t-\mathrm{Bu} \\
& 62 \mathrm{R}^{1}=\operatorname{MeS}\left(\mathrm{CH}_{2}\right)_{2}, \mathrm{R}^{2}=t-\mathrm{Bu}
\end{aligned}
$$

Kim 等 ${ }^{[15]}$ 报道了用一系列非对称性 Salen 配体 63 67 的钛配合物催化的芳香醛的不对称硅氧化反应. 其 中在 MCM-41 协助下配体 64 的钛配合物展现了优异的 催化活性，产物手性氰醇硅醚 ee 值高达 94\%.
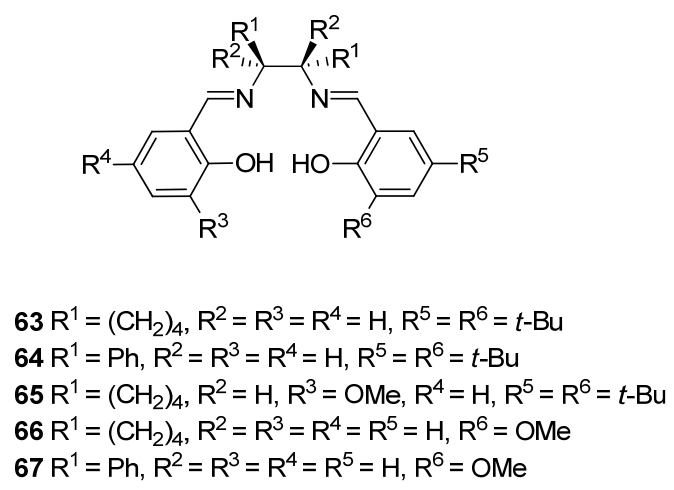

1996 年 Jiang 课题组 ${ }^{[17]}$ 研究发现一系列 $C_{2}$ 对称性 席夫碱的钛配合物也可以催化醛的不对称硅氭化反应. 基于一些 Salen 配合物已经被成功运用到其他不对称反 应 $^{[16]}$, Jiang 小组 ${ }^{[17]}$ 合成一系列 1,2-二苯基乙二胺以及水 杨醛衍生的配体，其中配体 68 的钛配合物对于三甲基 氧硅烷与苯甲醛反应得到手性氰醇硅醚展现了良好的 催化活性(ee 值高达 87\%).

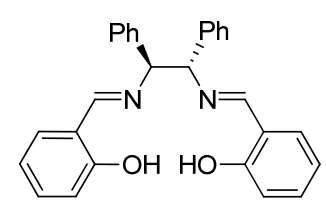

68

在同一时间 Belokon 和 North 等 ${ }^{[18]}$ 研究了基于 1,2二氨基环已烷 Salen 配体 69 70 的钛配合物, 为了区别
于 Jiang 的工作, 他们发现取代水杨醛环能提高反应体 系活性，如配体 70 的钛配合物催化三甲基氰硅烷与 4 种不同醛反应得到手性氰醇硅醚，收率 $55 \%$ ～70\%，对 映选择性 $62 \% \sim 77 \%$.

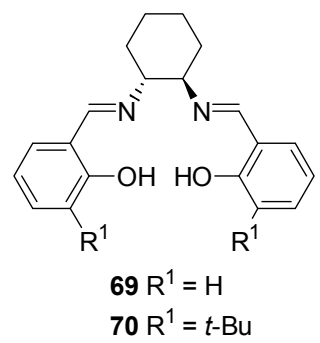

在 Salen 配体 69 70 研究的基础上, Belokon 和 Rozenberg 等 ${ }^{[19]}$ 基于平面手性 FHPC 和二胺合成了一些 Salen 配体 71 73. 研究发现, 其中配体 71 的钛配合物 为最佳催化剂, 通过三甲基氰硅烷与苯甲醛在 $-78{ }^{\circ} \mathrm{C}$ 二氯甲烷中反应 $120 \mathrm{~h}$ 得到手性氰醇硅醚, 收率可达 $90 \%$ ，对映选择性可达 $84 \%$.
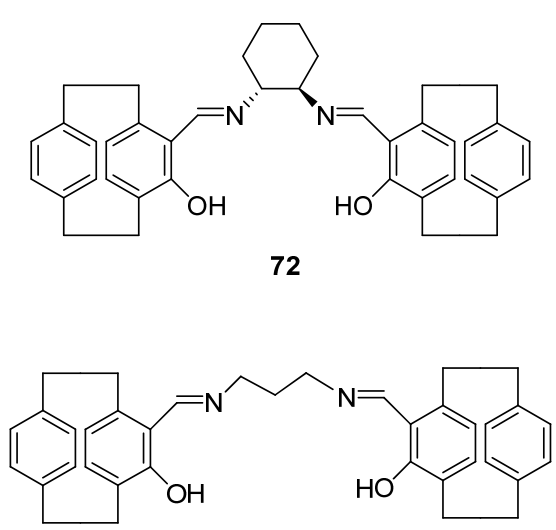

73

为了进一步优化配体 $\mathbf{7 0}$ 的结构, Belokon 和 North 等 ${ }^{[20]}$ 继续篮选了含不同取代基的 Salen 配体 74 78, 发 现配体 76 的钛配合物对于催化醛的不对称硅氰化反应 展现了优异的对映选择性(ee 值高达 $88 \%$ ).

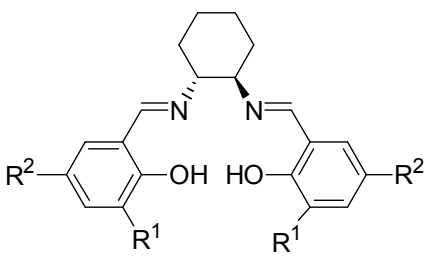

$$
\begin{aligned}
& 74 \mathrm{R}^{1}=t-\mathrm{Bu}, \mathrm{R}^{2}=\mathrm{Me} \\
& 75 \mathrm{R}^{1}=t-\mathrm{Bu}, \mathrm{R}^{2}=\mathrm{OMe} \\
& 76 \mathrm{R}^{1}=\mathrm{R}^{2}=t-\mathrm{Bu} \\
& 77 \mathrm{R}^{1}=\mathrm{R}^{2}=\mathrm{Cl}
\end{aligned}
$$




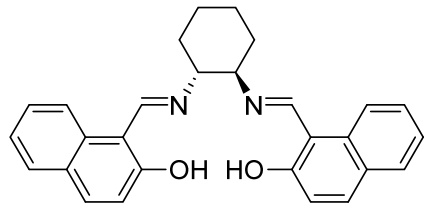

78

2010 年 Sun 课题组 ${ }^{[21]}$ 基于 Salen 配体合成了两个新 的四齿配体 79 和 80 , 然后与四异丙醇钛络合成功应用 到醛的不对称硅氰化反应, 以中等到良好的对映选择性 得到手性氰醇硅醚. 随后在 2011 年 Sun 课题组 ${ }^{[22]}$ 又合 成了手性吡咯烷二聚 Salen 配体 81, 通过与四异丙醇钛 络合催化三甲基氰硅烷与醛反应顺利合成手性氰醇硅 醚，对映选择性 $13 \% \sim 86 \%$. 相比于之前的四齿配体， 配体 81 的钛配合物在温和条件下 (在 $0{ }^{\circ} \mathrm{C}$ ) 展现了良好 的催化活性和对映选择性.

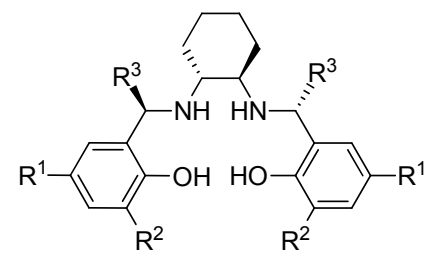

$79 \mathrm{R}^{1}=t-\mathrm{Bu}, \mathrm{R}^{2}=t-\mathrm{Bu}, \mathrm{R}^{3}=\mathrm{Ph}$

$80 R^{1}=H, R^{2}=P h, R^{3}=P h$

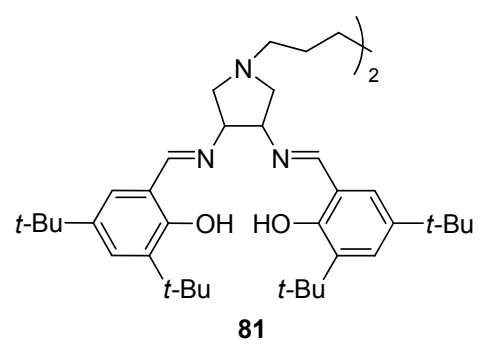

钛配合物的主要缺点是它们的分离和表征比较困 难, 1998 年 Belokon 和 North 成功分离和表征了二氯化 钛配合物 $82 \sim 87$, 并成功应用到苯甲醛的不对称三甲 基硅氰化反应，对映选择性 $18 \% \sim 86 \%$. 他们观察到添 加剂可能是导致高收率的因素之一, 如微量水, 而在严 格无水条件下配体 76 的钛配合物和配合物 85 都没有表 现出良好的催化活性. Belokon 和 North 等 ${ }^{[23]}$ 推测反应体 系中可能存在活性中间体, 于是将配合物 85 与 1 倍量水 反应, 最终分离得到双金属配合物 88 90. 其中用 0.1 $\mathrm{mol} \%$ 配合物 89 仅仅在室温条件下 $1 \mathrm{~h}$ 时间内就能使酫 完全转化为氰醇硅醚. 随后 Belokon 和 North 等 ${ }^{[24]}$ 还将 配合物 89 成功应用到合成不对称氰醇酯, 氭醇碳酸盐 类化合物当中.
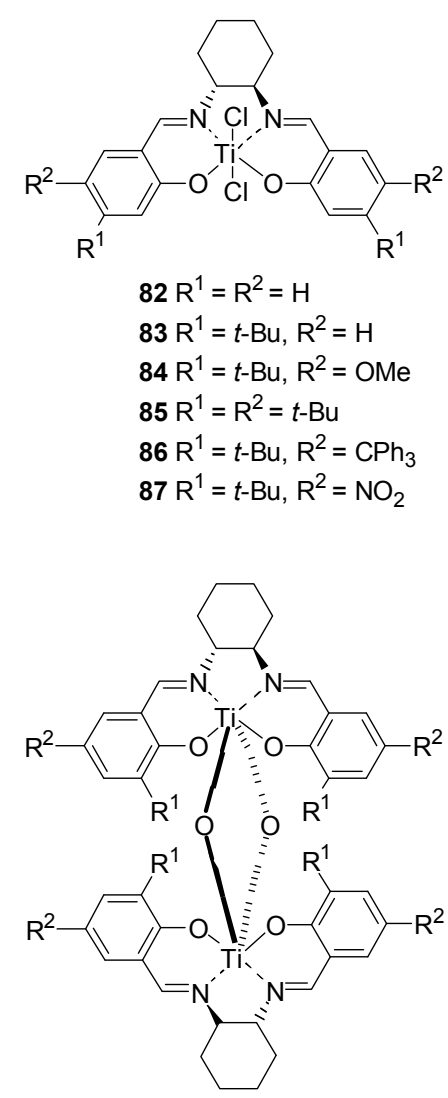

$$
\begin{aligned}
& 88 \mathrm{R}^{1}=\mathrm{R}^{2}=\mathrm{H} \\
& 89 \mathrm{R}^{1}=\mathrm{R}^{2}=t-\mathrm{Bu} \\
& 90 \mathrm{R}^{1}=t-\mathrm{Bu}, \mathrm{R}^{2}=\mathrm{NO}_{2}
\end{aligned}
$$

Che 等 ${ }^{[25]}$ 基于 BINAM 制备了一些新的配体 91 100, 并将它们的钛配合物应用到苯甲醛的不对称硅氰 化反应，经水解得到手性苯乙醇腈，收率 53\% 94\%, 对映选择性 24\% 93\%. 其中配体 94 的钛配合物展现了 优异的催化活性(ee 高达 93\%).<smiles>[R]c1cc([R])c(O)c(C=Nc2ccc3ccccc3c2-c2c(/N=C/c3cc([R])c([R])cc3O)ccc3ccccc23)c1</smiles>

$\mathrm{Pu}$ 等 ${ }^{[26]}$ 已经成功将配体 $101 \sim 105$ 应用到炔烃对醛 的加成反应当中, 紧接着该小组 ${ }^{[27]}$ 将这些配体与四异 丙醇钛络合尝试催化苯甲醛的不对称硅氰化反应. 研究 发现, 以配体 104 (12 mol\%)的钛配合物为催化剂, 在一 $20{ }^{\circ} \mathrm{C}$ 二氯甲烷中反应 $4 \mathrm{~h}$, 得到手性氰醇硅醚的对映选 择性最优 $(89 \% e e)$. 


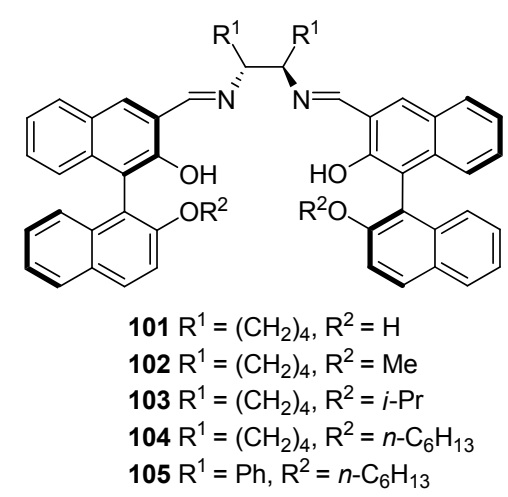

2007 年 Zhou 等 ${ }^{[28]}$ 报道了以 $C_{2}$ 对称性席夫碱配体 106 的铁配合物作为催化剂, 通过三甲基氧硅烷与醛不 对称加成顺利得到手性氧醇, 收率 75\% 97\%, 对映选 择性 48\% 76\%. 其中邻氯苯甲醛与三甲基氰硅烷反应 的对映选择性最优异.

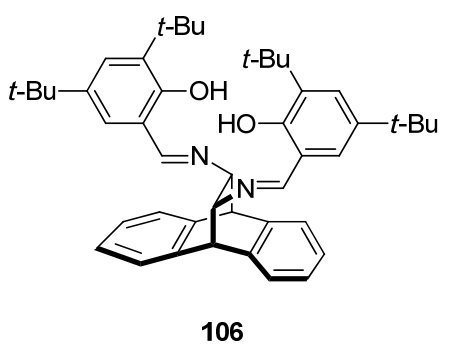

1986 年 Reetz 等 ${ }^{[29]}$ 率先将 BINOL 基钛配合物应用 到醛的不对称硅腈化反应. 研究发现, 以 $20 \mathrm{~mol} \%$ 配合 物 107 为催化剂, 甲苯为溶剂, 在 $-78{ }^{\circ} \mathrm{C}$ 中反应 $4 \mathrm{~h}$ 可 以催化异丁醛转化为相应的氰醇硅醚, 收率 $85 \%$, 对映 选择性 $82 \%$. 然而产物的绝对构型在当时没有被确 定. 随后 Nakai 等 ${ }^{[30]}$ 也报道了具有相同骨架的手性配合 物 108 催化的类似反应，收率 $0 \% \sim 78 \%$, 对映选择性 $43 \% \sim 98 \%$.

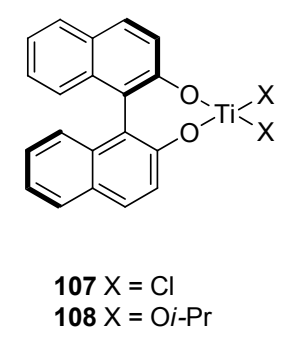

2006 年 Belokon 等 ${ }^{[31]}$ 经 $(R)$-BINOL 四步合成含 $(S)$ 颉基的配体 109, 然后与 2 倍量四异丙氧基钛原位络合 催化三甲基氰硅烷与苯甲醛反应得到手性氧醇硅醚, 对 映选择性可达 $86 \%$. 该小组随后继续尝试将配体 109 的 钛配合物应用到酮的不对称硅氧化反应, 然而催化剂对 于此反应没展现出良好的催化活性.<smiles>CC(C)CCc1cc2ccccc2c(-c2c(CCC(CO)C(C)C)cc3ccccc3c2O)c1O</smiles>

1995 年 Bolm 和 Muller ${ }^{[32]}$ 首次将手性亚胺的钛配合 物应用到不对称硅氧化反应. 以配体 110 的钛配合物为 催化剂, 通过三甲基氰硅烷与醛不对称加成得到手性氧 醇硅醚，收率 60\% 92\%，对映选择性 76\% 91\%.<smiles>NS(=O)(=O)c1ccccc1O</smiles>

除了手性亚胺钛催化剂外, 1999 年 Buono 和 Shibasaki 等 ${ }^{[33,34]}$ 率先报道了双官能团配体在不对称硅 氰化反应的应用. Buono 小组 ${ }^{[34]}$ 发现在室温条件下将配 体 111 与四异丙醇钛以 $1: 4$ 络合催化酫的三甲基氧硅 氧化反应得到手性氧醇硅醚，对映选择性高达 $98 \%$. Tang 课题组 ${ }^{[35]}$ 也研究了与配体 $\mathbf{1 1 1}$ 相似骨架的配体 112, 其铁配合物催化此反应顺利得到手性氧醇硅醚, 收率 $80 \% \sim 98 \%$, 对映选择性 8\% 90\%.

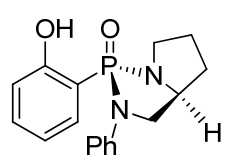

111

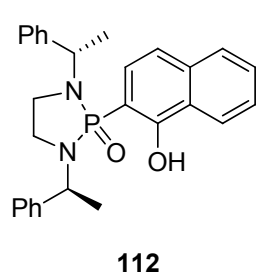

112
含亚砜配体的双官能团钛催化剂也被化学工作者 们所研究. Rowlands ${ }^{[36]}$ 合成了一些噁唑啉和亚砜基团框 架的配体 113 117, 与四异丙醇钛络合测试苯甲醛的不 对称硅氰化反应. 研究发现, 配体 114 的钛配合物催化 该反应得到产物的对映选择性最优(收率 $95 \%, 60 \% e e$ ), 这也说明弱性路易斯碱亚砜的存在也是导致催化剂具 有活性的关键因素.

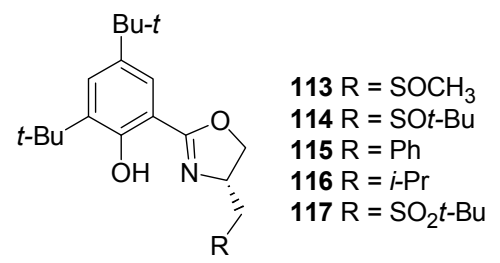

2007 年 Feng 等 ${ }^{[37]}$ 发现含氮氧化物的双官能团配体 118 129 的钛配合物也可以催化醛的不对称硅氰化反 应. 以苯甲醛作为底物, 反应 $48 \sim 52 \mathrm{~h}$ 后得到手性 
$\alpha$-(三甲基硅氧基)苯乙腈，收率 34\% 88\%, 对映选择 性 37\% 66\%.<smiles>[R]NC(=O)C1CC2CCCC2N1Cc1cccc[n+]1[O-]</smiles>

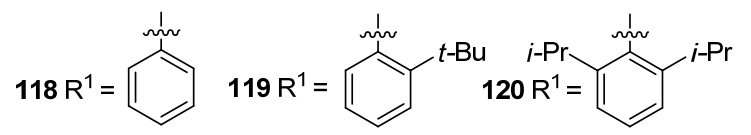

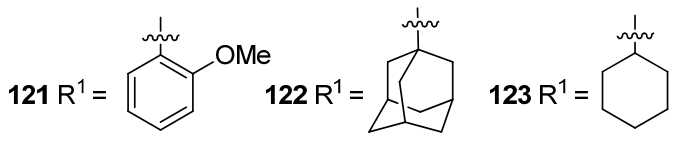
$124 \mathrm{R}^{1}=$ - $\left\{\begin{array}{c}\text { Ph } \\ \mathrm{P}\end{array}\right.$<smiles>C[n+]1ccccc1C(NC(=O)C1CC2C(CC3CCCC3N2Cc2ccccc2)CC1C(=O)NC(c1ccccc1)c1ccccc1)c1ccccc1</smiles>

2004 年 Zhou 等 ${ }^{[38]}$ 报道了樟脑型配体 130 131 的 双官团钛配合物实现的芳香醛的不对称硅氰化反应. 其 中以配体 130 的钛配合物为催化剂, 三甲基氰硅烷与对 甲氧基苯甲醛反应得到相应手性氧醇硅醚的对映选择 性最优异 $98 \% e e$ ).

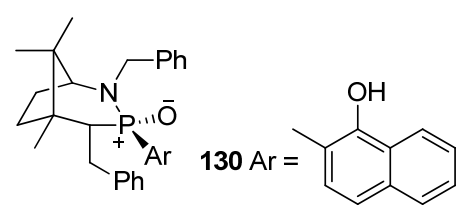<smiles>Cc1ccccc1O</smiles>

2011 年 $\mathrm{Lu}$ 课题组 ${ }^{[39]}$ 合成了在其中一个芳香环 3 位 上为二苯基氧膦的 Salen 配体 132, 与四异丙醇钛络合 作为一个单金属双官能团催化剂并成功应用到醛的不 对称硅氰化反应. 研究发现, 与无三苯基氧膦的二元体 系相比, 该体系具有比较高的催化活性 $(26 \% \sim 70 \% e e)$, 并且 $\mathrm{Lu}$ 小组还观察到该反应是分子内协同催化的过程, 路易斯酸中心金属钛和路易斯碱三苯基氧膦同时分别 活化醛和三甲基氰硅烷.

\section{3 钒配合物催化体系}

2000 年 Belokon 和 North 等 ${ }^{[40]}$ 率先基于四价钒描绘 了一种新型催化体系, 通过硫酸氧钒(IV)与席夫碱配体 76 成功合成了钒配合物 133, 并实现了三甲基氰硅烷对 芳香醛的不对称加成. 研究发现, 只需 $0.1 \mathrm{~mol} \%$ 的催化<smiles>CC(C)(C)c1cc(C=NC2CCCCC2N=Cc2cc(C(C)(C)C)cc(C(C)(C)C)c2O)c(O)c(C(C)(C)C)c1</smiles>

132

剂, 在室温反应 $24 \mathrm{~h}$ 得到手性㲵醇硅醚, 转化率 $100 \%$, 对映选择性 90\% 95\%. 相比于之前的钛配合物 89, 虽 然钒配合物 133 催化此反应时间较长, 但对于任何底物 醛都能达到较优异的对映选择性. 另外他们还研究了酮 的不对称氰硅化反应, 但未能得到预期的结果. 2009 年 $\mathrm{Li}$ 和 Yang 等 ${ }^{[41}$ 通过硅烷化方法微调 SBA-16 孔径并成 功将配合物 133 限制在纳米笼中. 此策略实现了在催化 过程中反应物和产物的自由扩散, 有效提高了催化剂反 应活性. 以三甲基氰硅烷和醛为原料，得到手性氰醇硅 醚对映选择性高达 $90 \%$.

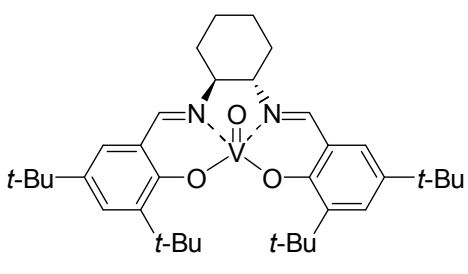

133

反应结束后对催化剂的分离需要经过很多繁琐的 工作才能完成, 2015 年 Amin 等 ${ }^{[42]}$ 克服了这个难题, 通 过将催化剂固化到磁性纳米粒子上, 待反应结束后利用 磁性就很容易将催化剂从反应体系中分离. 并且磁性纳 米粒子稳定且适用于除了强酸和强腐蚀外的任何化学 环境. 该课题组制备了负载磁性纳米粒子 $\mathrm{Fe}_{3} \mathrm{O}_{4}$ 的手性 钒伪麻黄碱配合物 134, 在室温无溶剂条件下实现了醛 的不对称氭硅化反应，产物手性氭醇硅醚对映选择性 $8 \% \sim 25 \%$. 研究发现, 催化剂的活性和对映选择性在重 复使用 15 次后仅有很少的损失.

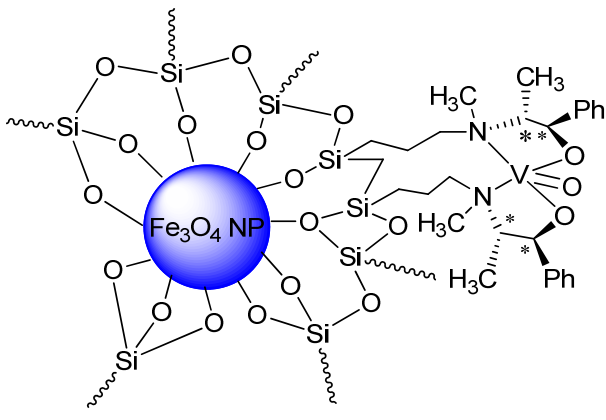

134 


\section{4 钒和钛的异核双金属催化体系}

基于配合物 89 催化反应速率快和配合物 133 催化 活性高的优点, 2004 年 Beloko 和 North 等 ${ }^{[43]}$ 将环已二胺 异构体衍生配合物 89 和配合物 $133 \mathrm{a}$ (配合物 133 在乙醇 中经空气氧化得到)混合, 作者预测该混合体系的催化 性能更倾向于钛配合物 89, 并且依附钛离子的 Salen 配 体的立体构型将决定产物氧醇构型. 通过将 $(S, S)$-配合 物 133a 和 $(R, R)$-配合物 89 以 $2: 1$ 混合催化三甲基氰硅 烷对苯甲醛的不对称加成, 得到 $(R)-\alpha$-(三甲基硅氧基) 苯乙腈, 对映选择性 $82 \%$, 结果说明, 产物的构型是由 依附钒离子的 Salen 配体决定的. 随后作者又研究了一 些由手性和非手性 Salen 配体制备的钛和钒催化剂, 结 果再次证明当钒和钛催化剂结合时不对称诱导在很大 程度上取决于钒催化剂的性质。

\section{5 锡基催化体系}

1991 年 Kobayashi 等 ${ }^{[44]}$ 首次将手性路易斯酸锡 $\mathbf{1 3 5}$ 应用于脂肪酫的不对称硅氰化反应. 在 $-78{ }^{\circ} \mathrm{C}$ 二氯甲 烷中反应 $14 \mathrm{~h}$, 得到手性氰醇硅醚, 收率为 $49 \% \sim 89 \%$, 对映选择性为 $72 \% \sim 96 \%$. 值得注意的是, 以苯甲醛作 为底物时没有得到相应产物.

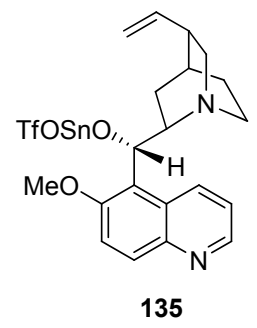

\section{6 镁基催化体系}

1993 年 Corey 和 Wang 首次报道了镁配合物介入合 成手性氰醇的方法 ${ }^{[45]}$. 将配体 136 和镁配合物 137 以 $3: 5$ 比例混合作用于酫的不对称硅氰化反应, 产物手 性氰醇硅醚对映选择性 $52 \%$ \% $95 \%$. 他们的这项工作也 是第一个报道了将路易斯酸和路易斯碱结合同时分别 活化醛和三甲基氧硅烷, 随后这个概念也被其他化学工 作者们所尝试.
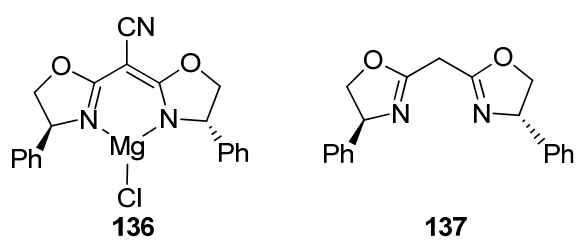

\section{7 钇基催化体系}

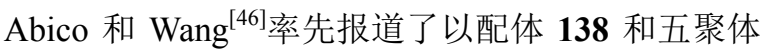
异丙醇钎制备的钎配合物实现的醛的不对称硅氧化反 应. 研究发现, 以芳香酫作为底物(不包括强吸电子官
能团底物), 只需 $0.2 \mathrm{~mol} \%$ 的催化剂就可以得到收率在 95\% 98\%的手性氧醇硅醚，对映选择性 $81 \% \sim 90 \%$. 虽然该催化剂的结构没有被确切表征出来，但作者随后 基于实验数据提出了可能的反应机理.

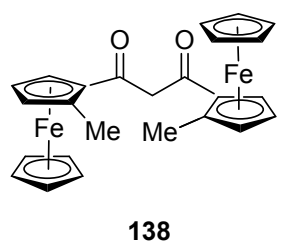

\section{8 镧系元素催化体系}

1998 年 $\mathrm{Qian}$ 等 ${ }^{[47]}$ 率先以 $\mathrm{La}(\mathrm{O} t-\mathrm{Bu})_{3}$ 和 $(S)-3,3^{\prime}-$ 双 (2甲氧基)联䒺酚(139)合成了手性镧催化剂，并成功应用 到醛的不对称硅氧化反应, 得到产物手性氰醇硅醚对映 选择性可达 $71 \%$. Greeves 等 ${ }^{[48]}$ 也报道了以三氯化锞和 二噁唑啉吡啶配体 140 制备的镧配合物为催化剂, 通过 三甲基氰硅烷与醛不对称加成顺利合成了手性氰醇硅 醚，对映选择性可达 $89 \%$. Fang 和 Yang 等 ${ }^{[49]}$ 发现由氯化 钐和手性磷 $(\mathrm{V})$ 配体制备的催化剂对芳香醛的不对称㲵 硅化反应具有良好的催化活性, 只需 $0.2 \mathrm{~mol} \%$ 的催化剂 生成手性氧醇硅梄就能达到较优异的对映选择( ee 值可 高达 90\%). 2006 年 Vale 课题组 ${ }^{[50]}$ 以 $30 \mathrm{~mol} \% \mathrm{~N}$-(对甲苯 磺酰基)- $L$-苯丙氨酸作为手性配体, 用一种销配合物 141 也实现了苯甲醛的不对称硅氭化反应，收率可达 $85 \%$ ，对映选择性可达 $85 \%$.
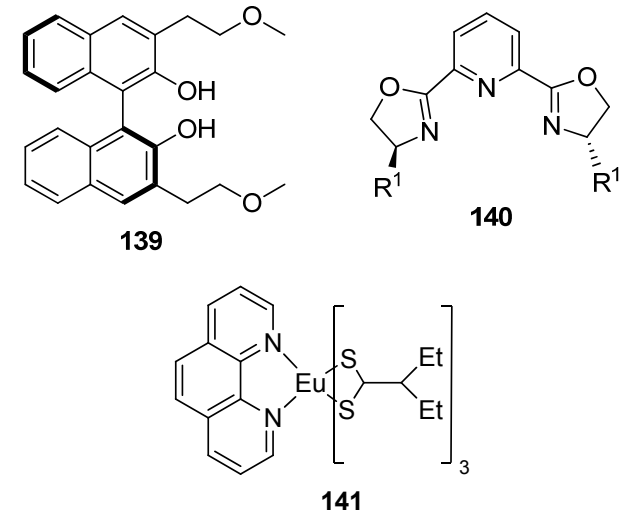

\section{9 锰基催化体系}

2005 年 $\mathrm{Kim}$ 和 $\mathrm{Lee}^{[51]}$ 首次发现在三苯基氧膦存在 下碱金属锰配合物 $\mathbf{1 4 2}$ 能催化三甲基氰硅烷与醛反应得 到手性㲵醇硅醚，收率 82\% 96\%，对映选择性 44\% $62 \%$. Katsuki 等 ${ }^{[52]}$ 已经报道了配合物 143 催化的烯烃的 环氧化反应，随后 Kim 课题组 ${ }^{[53]}$ 成功将其应用于芳香 醛的不对称硅氧化反应. 以三甲基氰硅烷和苯甲醛为原 料, 三苯基氧膦为助催化剂, 在 $0{ }^{\circ} \mathrm{C}$ 反应 $80 \mathrm{~h}$, 得到 $\alpha$-(三甲基硅氧基)苯乙腈，对映选择性为 $65 \%$. 

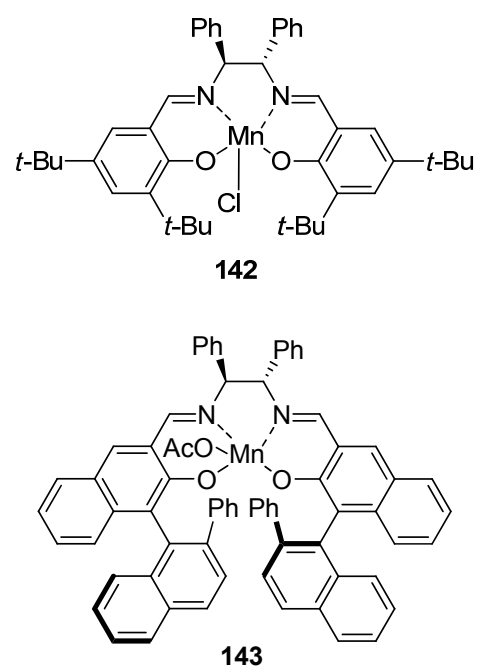

之前 Salen 锰配合物催化的醛的不对硅氰化反应, 产物只有中等至良好的收率和较低的对映选择性. 2015 年 $\mathrm{Xu}$ 课题组 ${ }^{[54]}$ 首次发现含两个可旋转苄基的 Ar-BINMOL 衍生 Salen 锰配合物 144 对于催化三甲基氰 硅烷与醛反应得到手性㲵醇硅醚显示了优异的催化活 性和对映选择性, 收率高达 $94 \%$, 对映选择性高达 $90 \%$ 。 就产率和对映选择性而言, 该催化剂的性能明显优于其 他 Salen 镇催化剂. 另外, 他们还发现该催化剂的功能 部分相似于生物类催化剂.

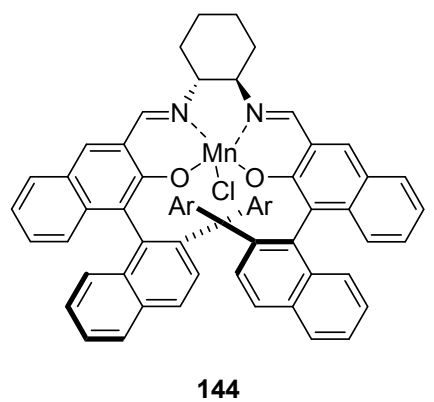

\subsection{0 铋基催化体系}

1997 年 Wada 和 Smith 等 ${ }^{[55]}$ 首次报道了铋配合物催 化的不对硅氰化反应. 以三氯化铋和 $L$-二乙基酒石酸 (145)制备铋配合物并催化三甲基氰硅烷与一系列醛不 对称加成, 经酸处理后得到手性㲵醇, 对映选择性 $20 \% \sim 73 \%$.

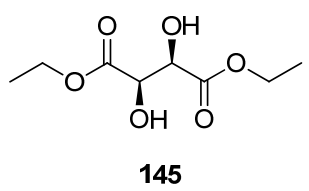

\subsection{1 铝基催化剂体系}

尽管之前 Inoue 的肽钛配合物没有通过三甲基氰硅 烷与醛反应得到手性氧醇, 而肽铝配合物却成功催化了
此反应，如以三甲基铝和肽 146 制备的肽铝配合物，手 性氰醇硅梄收率 66\% 92\%, 对映选择性 37\% 71\% ${ }^{[56]}$.

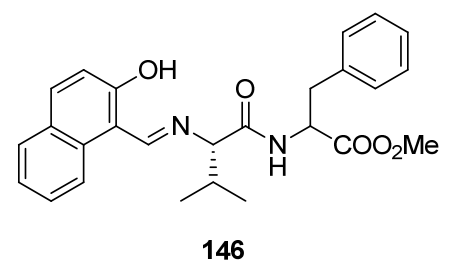

Kim 和 Song ${ }^{[57]}$ 发现在三苯基氧膦和氯化铝配合物 147 的协同催化下作用下，三甲基氰硅烷与一系列醛也 可以顺利得到手性氰醇硅醚，收率 $91 \% \sim 96 \%$, 对映选 择性 72\% $86 \%$. 2008 年 Zhou 等 ${ }^{[58]}$ 报道了在三辛基氧 化膦存在下铝配合物 148 催化的酫的不对称硅氰化反 应，得到手性氰醇硅醚收率高达 $94 \%$, 对映选择性高达 $92 \%$.
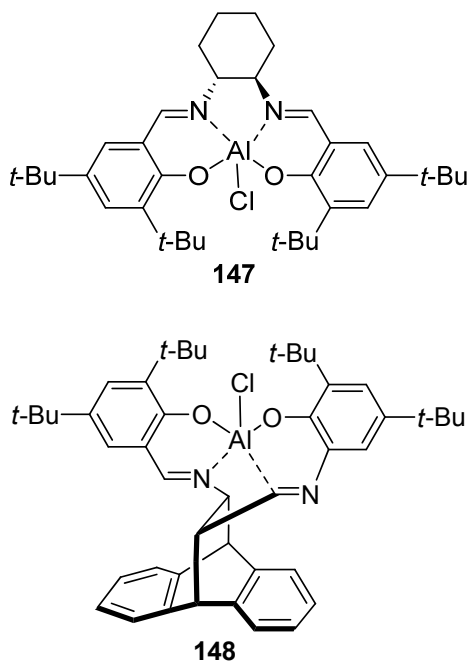

2009 年 North 小组 ${ }^{[59]}$ 首次报道了双金属 Salen 铝配 合物 149 催化的三甲基氰硅烷与一系列醛的不对称加成 反应，在 $-40{ }^{\circ} \mathrm{C} 10 \mathrm{~mol} \%$ 三苯基氧膦存在下得到手性 氧醇硅醚，对映选择性 $53 \% \sim 96 \%$. 动力学研究表明， 该反应为一级反应且反应速率与醛的浓度有关. 随后 2012 年 North 等 ${ }^{[60]}$ 又合成了与配合物 $\mathbf{1 4 9}$ 具有类似骨架 的双金属 Salen 铝配合物 150, 并成功应用到醛的不对 称硅氰化反应. 以三苯基氧膦为助催化剂, 在室温中加 入 $1 \mathrm{~mol} \%$ 催化剂得到手性氧醇硅醚，对映选择性 $32 \% \sim 78 \%$.

Shibasaki 课题组 ${ }^{[61]}$ 基于 BINOL 制备了配体 151, 并 发现该配体与三氯化铝络合对于催化三甲基氰硅烷与 醛不对称加成具有优异的催化活性，收率高达 $100 \%$, 对映选择性高达 $98 \%$. 该催化剂随后也被应用到合成天 然产物埃博霉素的反应当中 ${ }^{[62]}$. 在 Shibasaki 工作的基 础上, 2002 年 Nájera 和 Saá 等 ${ }^{[63]}$ 基于 BINOLAM 合成了 


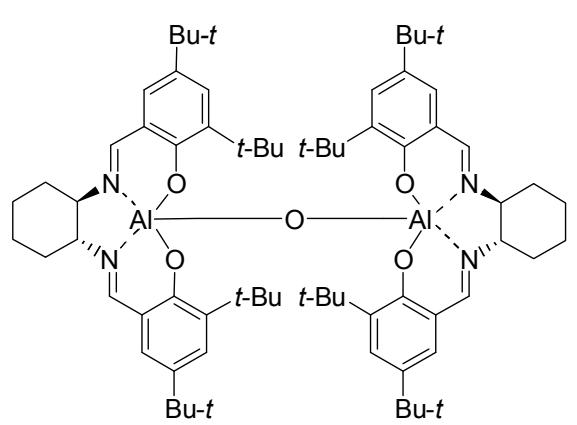

149

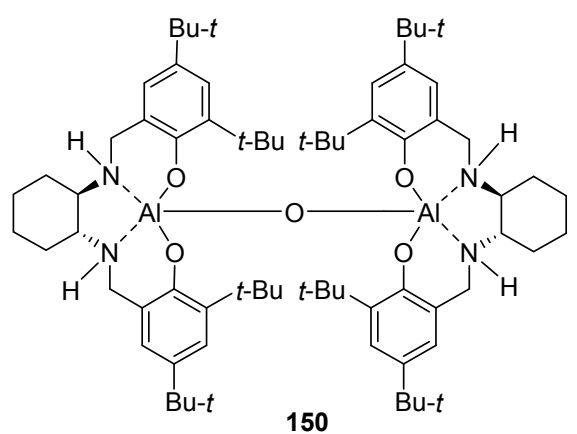

铝配合物 152, 在 $40 \mathrm{~mol} \%$ 三苯基氧膦和 $4 \AA$ 分子篮存 在下通过三甲基氧硅烷与一系列醛反应, 经酸处理后得 到手性氰醇, 收率 45\% 99\%, 对映选择性 66\% 98\%. 反应结束后经酸碱的简单处理催化剂可实现重复使用, 且催化活性基本没有损失.<smiles>CC(C)P(=O)(O)Cc1cc2ccccc2c(O)c1-c1c(O)c(CP(=O)(O)c2ccccc2)cc2ccccc12</smiles>

151

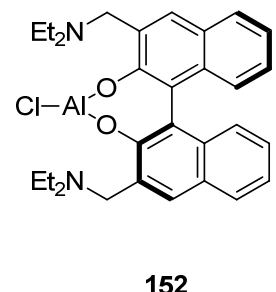

152
$\mathrm{Pu}$ 小组 ${ }^{[6]]}$ 由光学纯度联菜酚一步合成了配体 153 , 然后与二甲基氯化铝络合成功应用到醛的不对称硅氰 化反应. 研究发现, 以乙醚为溶剂, 在 $4 \AA$ 分子篎和 40 mol\% HMPA 存在下加入 $10 \mathrm{~mol} \%$ 催化剂室温反应 $24 \mathrm{~h}$, 得到手性氧醇硅醚, 收率高达 $94 \%$, 对映选择性高达 $98 \%$.

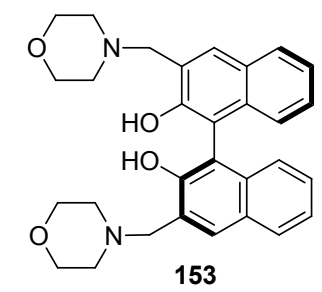

Iovel 等 ${ }^{[65]}$ 发现由二噁唑啉吡啶配体 154 和三氯化 铝原位形成的铝配合物可以催化三甲基氰硅烷与芳香
醛反应得到手性氰醇硅醚. 其中三甲基氰硅烷与苯甲醛 的反应，得到产物的对映选择性优异 $(90 \% e e)$.<smiles>CC(C)C1COC(c2cccc(C3=N[C@@H](C(C)C)CO3)n2)=N1</smiles>

154

Trost 课题组 ${ }^{[66]}$ 合成了配体 155, 并且成功应用到一 些不对称反应中, 这其中就包括醛的不对称氰化反应. 以配体 155 与三甲基铝络合的铝配合物为催化剂, 三甲 基氰硅烷和醛为原料，得到手性氧醇硅醚，收率 50\% $80 \%$, 对映选择性 $57 \% \sim 86 \%$.

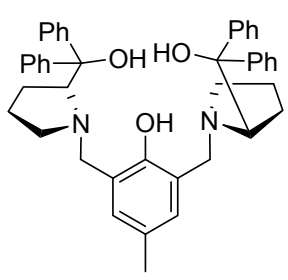

155

Shibasaki 课题组 ${ }^{[67]}$ 基于葡萄糖描绘了一类双官能 团配体体系, 以配体 156 的铝配合物 157 为催化剂, 通 过三甲基氰硅烷与醛不对称加成得到手性氧醇硅醚, 对 映选择性可达 $80 \%$. 该催化剂底物兼容性差，仅仅适用 于苯甲醛和一些脂肪族醛的不对称硅氰化反应.<smiles>O=P[PH2+](c1ccccc1)[C@H](O)[C@H]1OCC[C@@H](O)[C@@H]1O</smiles>

156

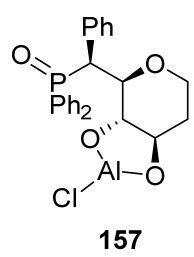

157
2012 年 Sun 等 ${ }^{\left[{ }^{[8]}\right.}$ 以含氮氧基团和吡咯烷基团的 Salen 配体 158 与二乙基氯化铝合成了 Salen 铝配合物 159, 并成功应用于三甲基氰硅烷与醛的不对称加成反 应, 在 $0{ }^{\circ} \mathrm{C}$ 反应 $10 \mathrm{~h}$ 得到手性氰醇硅醚, 收率 $16 \%$ $99 \%$, 对映选择性 $45 \%$ \% $92 \%$. 在一些不对称硅氧化反 应中, 通常需要加入一些路易斯碱来活化三甲基氰硅 烷，如三苯基氧膦. 而 Sun 小组发现 Salen 铝配合物 $\mathbf{1 5 9}$ 在无助催化剂三苯基氧膦存在下也能在温和条件下顺 利合成具有优异对映选择性的手性氭醇硅醚.

\subsection{2 手性碱催化剂}

Kagan 等 ${ }^{[69}$ 报道了手性酚基锂盐 160 催化的不对称 硅氰化反应. 以三甲基氰硅烷和醛为原料, 得到手性氰 醇硅醚，收率 73\% 99\%, 对映选择性 0\% 59\%. 他们 

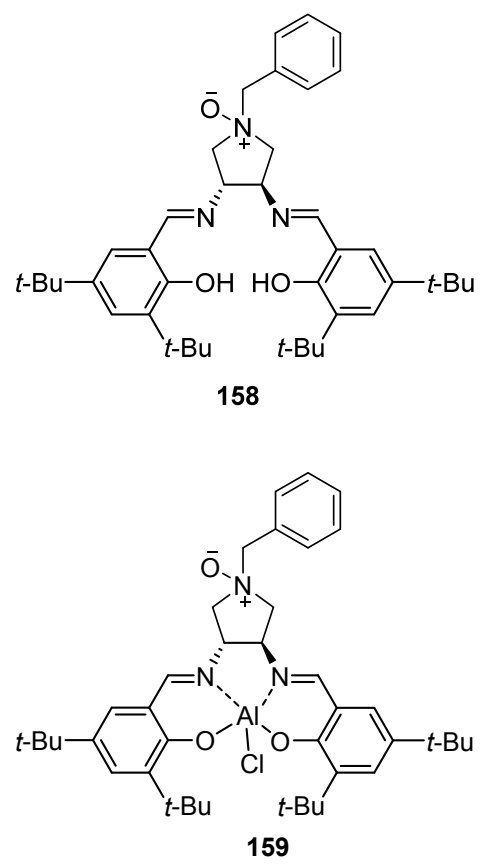

还发现配体 76 的单锂盐在此反应中的催化性能远远超 过手性酚基锂盐 160, 产物手性氧醇硅醚对映选择性高 达 $97 \%$. 然而该体系底物兼容性差, 反应时间过长(长达 $11 \mathrm{~d})$.

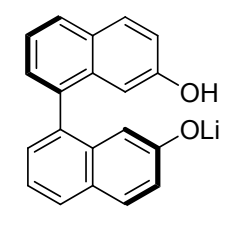

160

\subsection{3 氨基酸类聚合物催化体系}

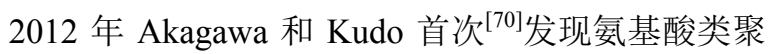
合物可以催化三甲基氰硅烷与醛的不对称加成反应. 以 负载 TentaGel 树脂的亮氨酸 (40 个) 链为催化剂, $-20{ }^{\circ} \mathrm{C}$ 二氯甲烷反应 $48 \mathrm{~h}$, 得到手性氰醇硅醚对映选 择性 $31 \% \sim 61 \%$.

\subsection{MOF 催化体系}

被称为配位聚合物的金属有机骨架 $(\mathrm{MOF})$ 是一类 具有特殊性质的新兴结晶化合物, 它不仅具有非常高的 孔隙率和表面积, 而且骨架结构易调控, 容易实现功能 化. 2014 年 Cui 课题组 ${ }^{[71]}$ 构建了以手性 2,2' -二羟基-1,1'联苯为配体的有机金属框架 $\mathbf{1 6 1}$, 经 $\mathrm{Li}$ 离子与二羟基的 其中一个质子交换后，该框架被证明是一种高效、可回 收的非均相催化剂, 并在共活化剂水存在下通过三甲基 氯硅烷与醛反应顺利得到手性氰醇硅醚, 收率高达 99\%, 对映选择性高达 $>99 \%$, 催化剂可重复使用 4 次 且活性基本没有损失. 为了实现该体系在有机合成中的
应用, Cui 小组成功将其应用到合成药物 $(S)$-丁呋洛尔反 应当中，产率高达 95\%，对映选择性高达 $98 \%$.

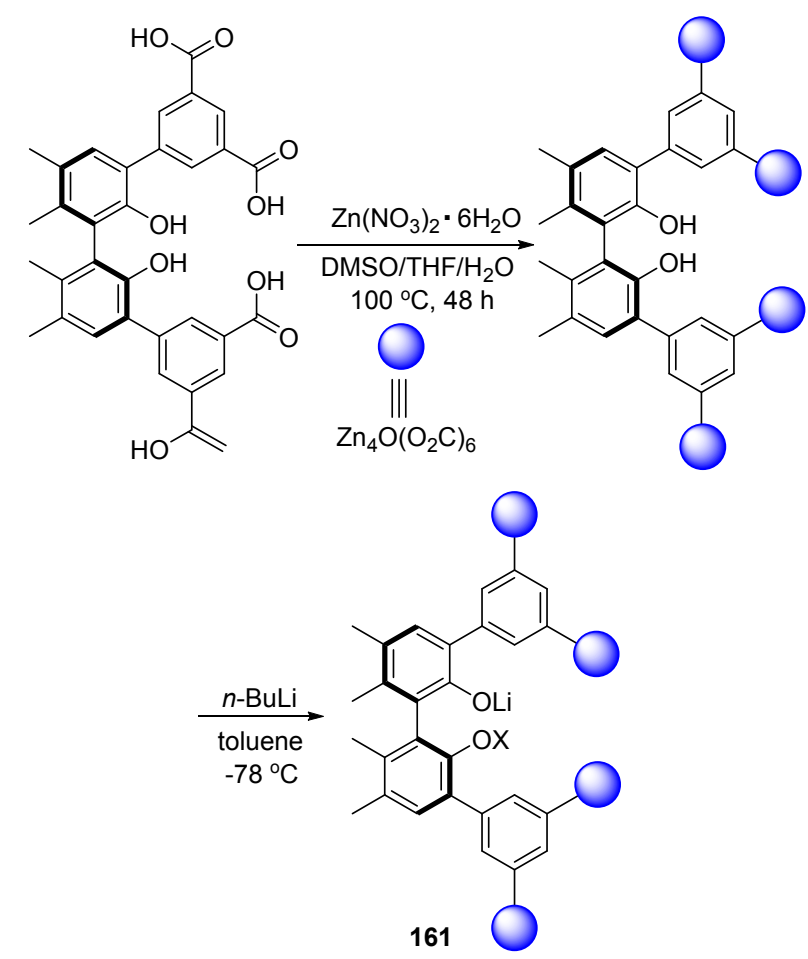

\section{2 酮的不对称硅荷化反应}

\section{1 嗍基催化体系}

基于催化剂 3 已经被成功运用到醛的不对称硅氧化 反应的基础上, 2005 年 Corey 课题组 ${ }^{[72]}$ 继续研究了其催 化的一系列甲基酮的不对称硅氰化反应. 在三苯基氧膦 存在下室温反应 3 $10 \mathrm{~d}$, 得到手性氰醇硅醚对映选择 性 32\% 96\%. 随后作者还发现与其具有类似骨架的化 合物 162 对于酮的不对称硅㲵化反应也具有良好的催化 活性，收率 45\% 92\%，对映选择性 $80 \% \sim 96 \%$. 然而 该体系的最大缺点是催化剂用量大，反应时间过长.

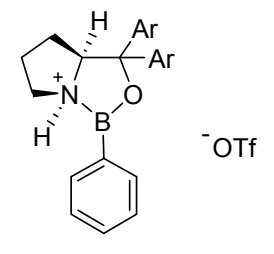

162

\section{2 钛基催化体系}

在 De Vries 工作的基础上, 1997 年 Choi 等 ${ }^{[73]}$ 首次报 道了化学催化的酮的不对称硅氰化反应. 以 163 作为催 化剂, 在 $0.8 \mathrm{GPa}$ 下二氯甲烷中实现了三甲基氰硅烷与 苯乙酮不对称加成得到手性氧醇，收率 $93 \%$, 对映选择 性 $60 \%$. 反应结束后该催化剂可以被分离和重复使用. 
<smiles></smiles>

基于之前双金属钛催化剂在醛的不对成硅氰化反 应中显示的优异结果, Belokon 和 North 等 ${ }^{[74]}$ 率先在大气 压力下实现了催化剂 89 催化的芳甲基酮和乙基酮的不 对称硅氰化反应, 手性氰醇收率 $64 \% \sim 100 \%$, 对映选择 性 32\% 72\%.

Shibasaki 等 ${ }^{[75]}$ 在研究双官能团铝配合物的同时发 现配体 164 的钛配合物也能够催化三甲基氰硅烷与酮反 应得到手性㲵醇硅醚，收率 $72 \%$ ～92\%，对映选择性 $69 \% \sim 92 \%$. Feng 和 Jiang 等 ${ }^{[76]}$ 也成功将双官能团配体 应用到酮的不对称硅氧化反应, 制备并篮选了一系列具 有氮氧基团配体的钣配合物, 发现配体 165 与四异丙氧 基钛 $1: 1.2$ 混合能够催化此反应得到手性氰醇硅醚, 收 率 61\% 87\%, 对映选择性 $25 \% \sim 69 \%$. Feng 等 ${ }^{[77]}$ 随后 又研究了在非手性路易斯碱性存在下路易斯酸配合物 催化的酮的不对称硅氰化反应. 在配体 166 的钛配合物 和非手性 $N$-氧化物 167 共同作用下, 得到手性氰醇的对 映选择性可达 $84 \%$.

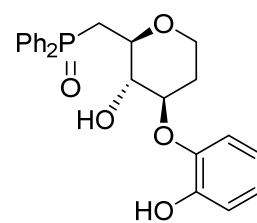

164

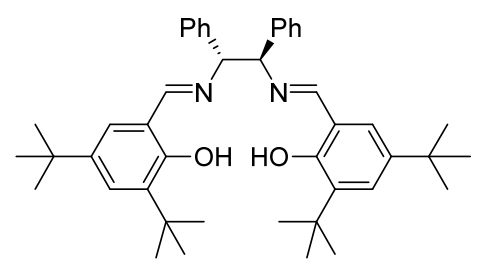

166

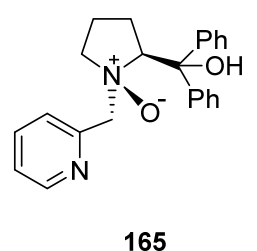

165<smiles>[O-]c1ccccc1</smiles>

167

\section{3 铜基催化剂体系}

2010 年 Rajagopal 课题组 ${ }^{[78]}$ 首次报道了负载聚合物 的 Salen 铜配合物催化的酮的不对称硅氧化反应. 在三 苯基氧膦存在下以负载 JandaJel 的 Salen 铜配合物 $\mathbf{1 6 8}$ 作为催化剂, 三甲基氰硅烷和酮为原料, 得到手性氭醇 硅醚收率 $83 \% \sim 94 \%$, 对映选择性 $52 \% \sim 84 \%$, 且催化 剂可反复使用 5 次.

\section{4 铝基催化剂体系}

Snapper 和 Hoveyda 等 ${ }^{[79]}$ 报道了在 $10 \mathrm{~mol} \%$ 异丙醇 铝和 $10 \mathrm{~mol} \%$ 甲醇存在下以 $10 \mathrm{~mol} \%$ 配体 169 顺利通过

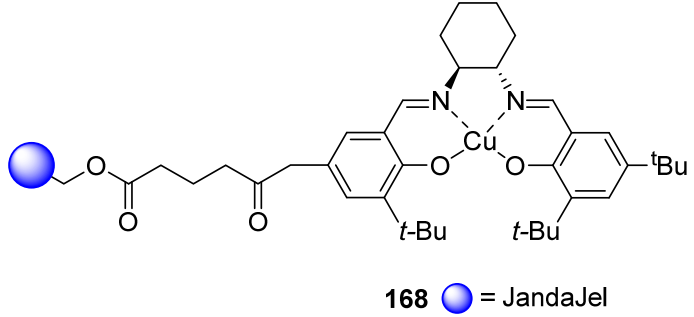

三甲基氰硅烷与酮不对称加成得到手性氰醇，收率 $67 \% \sim 97 \%$, 对映选择性 $82 \% \sim 95 \%$. 而且该配体对于 此反应展现了良好的底物兼容性.<smiles>COC(=O)CNC(=O)CC[C@H](NC(=O)CNC(=O)c1ccccc1)C(=O)N/C=C/c1cc(OC)ccc1O</smiles>

Feng 等 ${ }^{[80]}$ 发现在氮氧化物 $\mathbf{1 6 7}$ 存在下由配体 $\mathbf{1 7 0}$ 和三乙基铝形成的铝配合物能催化酮的不对称硅氧化 反应得到手性氧醇硅醚，收率高达 $99 \%$, 对映选择性高 达 94\%. 即 Salen 铝配合物 147 成功应用于醛的不对称 硅氰化反应之后, 2006 年 Kim 课题组 ${ }^{[81]}$ 又成功将其在酮 的不对称硅㲵化反应上得到了应用，产物手性氧醇硅醚 对映选择性可达 $92 \%$.<smiles>Oc1ccc(Br)cc1/C=N/C(c1ccccc1)c1ccccc1O</smiles>

170

\section{5 锰基催化剂体系}

在之前研究醛的不对称硅氰化反应基础上, Kim 课 题组 ${ }^{[82]}$ 发现在三苯基氧膦和锰配合物 142 协同催化下, 通过三甲基氰硅烷与酮不对称加成也能顺利得到手性 㲵醇硅醚，收率 38\% 95\%, 对映选择性 $46 \% \sim 82 \%$. 2009 年 Khan 等 ${ }^{[83]}$ 报道了以可回收的多聚和二聚 Salen 锰配合物 143 和 144 为主催化剂, 三苯基氧膦为助催化 剂，在室温二氯甲烷中实现了酮的不对称硅氰化反应， 反应 $24 \mathrm{~h}$ 得到手性氰醇硅醚, 产率可达 $98 \%$, 对映选择 性可达 $86 \%$. 对于大多数酮, 催化剂 143 展现了较催化 剂 144 稍好的催化活性和对映选择性, 同时这两种催化 剂都可以很容易地被回收重复利用 4 次且保持催化活性 不变.

\section{3 总结}

本文对已报道的三甲基氰硅烷与醛酮的不对称硅 


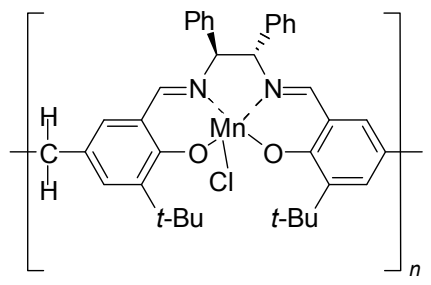

143

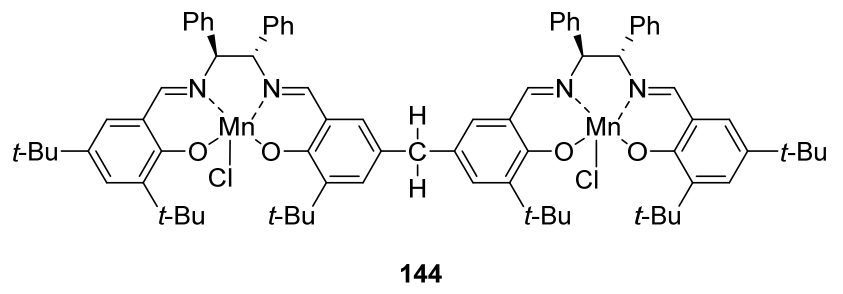

氰化反应中一些催化体系的发展进行了详述. 在过去的 三十年里, 化学介导合成手性氰醇有着显著的进步, 如 反应时间长、温度低、底物兼容差、催化剂用量多等缺 点也逐渐被一些新型催化体系所替代. 对于催化醛的不 对称氭硅化反应, 一些体系展现了底物适用范围广、选 择性高、催化剂用量少, 且能在温和条件下较短时间内 完成反应的优点, 如 Belokon 和 North 的钛和钒双金属 催化体系. 而近年出现的一些新型催化剂也展现了优异 的催化性能和对映选择性, 如 Cui 课题组构建的可回收 非均相 MOF 催化剂, 只需少量催化剂 $(0.5 \mathrm{~mol} \%)$ 在较短 时间内得到产物对映选择性高达 $>99 \%$. 而对于催化酮 的不对称氰硅化反应, 由起初在高压力条件下反应逐渐 发展到在环境压力下进行且催化剂选择性较高, 如 Belokon 和 North 的双金属钛催化体系. 虽然 Snapper 和 Hoveyd 的铝催化剂、Kim 和 Khan 的锰催化剂和 Rajagopal 的新型铜基体系等都是一些可选择的方法, 但仍存在一些关键性的挑战. 总之, 手性氰醇的催化不 对称合成研究还拥有更广阔的空间, 从反应机理上设计 出活性更好、适用范围更广、条件更温和、选择性更高 的催化剂仍是当前乃至今后继续研究的首要原则.

\section{References}

[1] (a) Breuer, M.; Ditrich, K.; Habicher, T.; Hauer, B.; Keler, M.; Stürmer, R.; Zelinski, T. Angew. Chem., Int. Ed. 2004, 43, 788.

(b) Ryu, D. H.; Corey, E. J. J. Am. Chem. Soc. 2004, 126, 8106. (c) Belokon, Y. N.; Blacker, A. J.; Carta, P.; Clutterbuck, L. A.; North, M. Tetrahedron 2004, 60, 10433.

[2] Chen, P. R.; Yan, C.; Zhang, Y. Chin. J. Org. Chem. 2010, 30, 662 (in Chinese).

(陈沛然, 颜超, 张怡, 有机化学, 2010, 30, 662.)

[3] Reetz, M. T.; Kunisch, F.; Heitmann, P. Tetrahedron Lett. 1986, 27, 4721.

[4] Narasaka, K.; Yamada, T.; Minamikawa, H. Chem. Lett. 1987, 2073.

[5] (a) Hayashi, M.; Matsuda, T.; Oguni, N. J. Chem. Soc. 1990, 1364. (b) Hayashi, M.; Matsuda, T.; Oguni, N. J. Chem. Soc. 1992, 3135.

[6] (a) Oku, J.; Ito, N.; Inoue, S. J. Makromol. Chem. 1979, 180, 1089. (b) Oku, J.; Inoue, S. J. Chem. Soc. 1981, 229.

[7] Mori, A.; Nitta, H.; Kudo, M.; Inoue, S. J. Tetrahedron Lett. 1991, $32,4333$.

[8] Hayashi, M.; Miyamoto, Y.; Inoue, T.; Oguni, N. J. Chem. Soc. 1991, 1752.

[9] Jiang, Y.; Zhou, X.; Hu, W.; Li, Z.; Mi, A. Tetrahedron: Asymmetry 1995, 6, 405.

[10] (a) Flores-Lopéz, L. Z.; Parra-Hake, M.; Somanathan, R.; Walsh, P. J. Organometallics 2000, 19, 2153.

(b) Gama, A.; Flores-Lope'z, L. Z.; Aguirre, G.; Parra-Hake, M.; Somanathan, R.; Walsh, P. J. Tetrahedron: Asymmetry 2002, 13, 149.

[11] (a) Yang, Z. H.; Wang, L. X.; Zhou, Z. H.; Zhou, Q L.; Tang, C. C. Tetrahedron: Asymmetry 2001, 12, 1579.

(b) Yang, Z. H.; Zhou, Z. H.; Tang, C. C. Synth. Commun. 2001, 19, 3031.

[12] Ewelina, B.; Mariusz, J. B.; Miroslaw, W.; Agnieszka, L.; Andrzej, W. Tetrahedron: Asymmetry 2014, 25, 554.

[13] Moreno, R. M.; Rosol, M.; Moyano, A. Tetrahedron: Asymmtry 2006, 17, 1089.

[14] Belokon, Y. N.; Chesnokov, A. A.; Ikonnikov, N.; Kublitsky, V. S.; Moscalenko, M.; North, M.; Orlova, S.; Tararov, V.; Yashkina, L. V. Russ. Chem. Bull. 1997, 46, 1936.

[15] Kim, G. J.; Shin, J. H. Catal. Lett. 1999, 63, 83.

[16] (a) Canali, L.; Sherrington, D. C. Chem. Soc. Rev. 1999, $28,85$.

(b) Katsuki, T. Adv. Synth. Catal. 2002, 344, 131.

(c) Yoon, T. P.; Jacobsen, E. N. Science 2003, 299, 169

(d) Katsuki, T. Synlett 2003, 281.

(e) Matsumoto, K.; Saito, B.; Katsuki, T. Chem. Commun. 2007, 3619 .

[17] (a) Pan, W.; Feng, X.; Gong, L.; Hu, W.; Li, Z.; Mi, A.; Jiang, Y. Synlett 1996, 337.

(b) Jiang, Y.; Gong, L.; Feng, X.; Hu, W.; Pan, W.; Li, Z.; Mi, A. Tetrahedron 1997, 53, 14327.

[18] Belokon, Y. N.; Ikonnikov, N. S.; Moscalenko, M. A.; North, M.; Orlova, S.; Tararov, V. I.; Yashkina, L. Tetrahedron: Asymmetry 1996, 7, 851.

[19] Belokon, Y. N.; Moscalenko, M. A.; Ikonnikov, N. S.; Yashkina, L.; Antonov, D.; Vorontsov, E.; Rozenberg, V. Tetrahedron: Asymmetry 1997, 8, 3245.

[20] Belokon, Y. N.; Flego, M.; Ikonnikov, N. S.; Moscalenko, M. A.; North, M.; Orizu, C.; Tararov, V. I.; Tasinazzo, M. J. Chem. Soc. 1997, 1293.

[21] Lv, C.; Wang, S.; Wu, M.; Xia, C.; Sun, W. Tetrahedron: Asymmetry 2010, 21, 1869.

[22] Lv, C.; Xu, D.; Wang, S.; Miao, C.; Xia, C.; Sun, W. Catal. Commun. 2011, 12, 1242.

[23] (a) Belokon, Y. N.; Caveda-Cepas, S.; Green, B.; Ikonnikov, N. S.; Khrustalev, V. N.; Larichev, V. S.; Moscalenko, M. A.; North, M.; Orizu, C.; Tararov, V. I.; Tasinazzo, M.; Timofeeva, G. I.; Yashkina, L. V. J. Am. Chem. Soc. 1999, 121, 3968.

(b) Kless, A.; Lefeber, C.; Spannenberg, A.; Kempe, R.; Baumann, W.; Holz, J.; Borner, A. Tetrahedron 1996, 52, 14599.

(c) Tsuchimoto, M. Chem. Soc. Jpn. 2001, 74, 2101.

(d) Davis, A.; Kilner, C. A.; Kee, T. P. Inorg. Chim. Acta 2004, $357,3493$.

[24] (a) Belokon, Y. N.; Gutnov, A. V.; Moscalenko, M. A.; Yashkina, L. V.; Lesovoy, D. E.; Ikonnikov, N. S.; Larichev, V. S.; North, M. Chem. Commun. 2002, 244.

(b) Belokon, Y. N.; Carta, P.; Gutnov, A. V.; Maleev, V. I.; Mos- 
kalenko, M. A.; Yashkina, L. V.; Ikonnikov, N.; Khrustalev, V. N.; North, M. Helv. Chim. Acta 2002, 85, 3301.

(c) Belokon, Y. N.; Blacker, A. J.; Clutterbuck, L. A.; North, M. Org. Lett. 2003, 5, 4505.

[25] Zhou, X. G.; Huang, J. S.; Ko, P. H.; Cheung, K. K.; Che, C. M. J. Chem. Soc., Dalton. Trans. 1999, 3303.

[26] Li, Z. B.; Pu, L. Org. Lett. 2004, 6, 1065.

[27] Li, Z. B.; Rajaram, A. R.; Decharin, N.; Qin, Y. C.; Pu, L. Tetrahedron Lett. 2005, 46, 2223.

[28] Zeng, Z.; Zhao, G.; Gao, P.; Tang, H.; Chen, B.; Zhou, Z.; Tang, C. Catal. Commun. 2007, 8, 1443.

[29] Reetz, M. T.; Kyung, S.-H.; Bolm, C.; Zierke, T. Chem. Ind. 1986, 824.

[30] Mori, M.; Imma, H.; Nakai, T. Tetrahedron Lett. 1997, 38, 6229.

[31] Belokon, Y. N.; Chusov, D.; Borkin, D. A.; Yashkina, L. V.; Dmitriev, A. V.; Katayev, D.; North, M. Tetrahedron: Asymmetry 2006, 17, 2328.

[32] Bolm, C.; Muller, P. Tetrahedron Lett. 1995, 36, 1625.

[33] (a) Hamashima, Y.; Sawada, D.; Kanai, M.; Shibasaki, M. J. Am. Chem. Soc. 1999, 121, 2641.

(b) Hamashima, Y.; Sawada, D.; Nogami, H.; Kanai, M.; Shibasaki, M. Tetrahedron 2001, 57, 805.

[34] Brunel, J. M.; Legrand, O.; Buono, G. Tetrahedron: Asymmetry 1999, 10, 1979.

[35] (a) Yang, Z. H.; Zhou, Z. H.; Wang, L. X.; Li, K. Y.; Zhou, Q. L.; Tang, C. C. Synth. Commun. 2002, 32, 2751.

(b) Yang, Z.; He, K.; Zhou, Z.; Wang, L.; Li, K.; Zhao, G.; Zhou, Q.; Tang, C. C. Tetrahedron: Asymmetry 2003, 14, 3937.

[36] Rowlands, G. J. Synlett 2003, 236.

[37] Wang, W.; Zhou, S.; Liu, X.; Feng, X. Tetrahedron 2007, 63, 5129.

[38] (a) He, K.; Zhou, Z.; Wang, L.; Li, K.; Zhao, G.; Zhou, Q.; Tang, C. Tetrahedron 2004, 60, 10505.

(b) He, K.; Zhou, Z.; Wang, L.; Li, K.; Zhao, G.; Zhou, Q.; Tang, C. Synlett 2004, 1521.

[39] Wen, Y. Q.; Ren, W. M.; Lu, X. B. Chin. Chem. Lett. 2011, 22, 1285.

[40] (a) Belokon, Y. N.; North, M.; Parsons, T. Org. Lett. 2000, 2, 1617. (b) Belokon, Y. N.; Green, B.; Ikonnikov, N. S.; North, M.; Parsons, T.; Tararov, V. I. Tetrahedron 2001, 57, 771.

[41] Yang, H. Q.; Zhang, L.; Wang, P.; Yang, Q. H.; Li, C. Green Chem. 2009, 11, 257.

[42] Amin, R.; Bahareh, A. Catal. Commun. 2015, 58, 80.

[43] (a) Belokon, Y. N.; North, M.; Maleev, V. I.; Voskoboev, N. V.; Moskalenko, M. A.; Peregudov, A. S.; Dmitriev, A. V.; Ikonnikov, N. S.; Kagan, H. B. Angew. Chem., Int. Ed. 2004, 43, 4085.

(b) Belokon, Y. N.; Clegg, W.; Harrington, R. W.; North, M.; Young, C. Tetrahedron 2007, 63, 5287.

(c) Belokon, Y. N.; Clegg, W.; Harrington, R. W.; North, M.; Young, C. Inorg. Chem. 2008, 47, 3801.

[44] Kobayashi, S.; Tsuchiya, Y.; Mukaiyama, T. Chem. Lett. 1991, 541.

[45] Corey, E. J.; Wang, Z. Tetrahedron Lett. 1993, 34, 4001.

[46] (a) Abiko, A.; Wang, G. Q. J. Org. Chem. 1996, 61, 2264. (b) Abiko, A.; Wang, G. Q. Tetrahedron 1998, 54, 11405.

[47] Qian, C.; Zhu, C.; Huang, T. J. Chem. Soc. 1998, 2131.

[48] (a) Aspinall, H. C.; Greeves, N. J.; Smith, P. M. Tetrahedron Lett. 1999, 40, 1763.

(b) Aspinall, H. C.; Greeves, N. J. Organomet. Chem. 2002, 647, 151.

(c) Aspinall, H. C.; Bickley, J. F.; Greeves, N. J.; Kelly, R. V.; Smith, P. M. Organometallics 2005, 24, 3458.

[49] Yang, W. B.; Fang, J. M. J. Org. Chem. 1998, 63, 1356.

[50] Vale, J. A.; Faustino, W. M.; Menezes, P. H.; Sá, G. F. Chem. Com- mun. 2006, 3340.

[51] Kim, S. S.; Lee, S. H. Synth. Commun. 2005, 35, 751.

[52] Irie, R.; Noda, K.; Ito, Y.; Matsumoto, N.; Katsuki, T. Tetrahedron Lett. 1990, 31, 7345 .

[53] Kim, S. S.; Kwak, J. M.; George, S. C. Appl. Organomet. Chem. 2007, 21, 809.

[54] Wei, Y. L.; Huang, W. S.; Cui, Y. M.; Yang, K. F.; Xua, Z.; Xu, W. L. $R S C A d v .2015,5,3098$.

[55] Wada, M.; Takahashi, T.; Domae, T.; Fukuma, T.; Miyoshi, N.; Smith, K. Tetrahedron: Asymmetry 1997, 8, 3939.

[56] (a) Mori, A.; Ohno, H.; Nitta, H.; Tanaka, K.; Inoue, S. Synlett 1991, 563.

(b) Ohno, H.; Nitta, H.; Tanaka, K.; Mori, A.; Inoue, S. J. Org. Chem. 1992, 57, 6778.

[57] (a) Kim, S. S.; Song, D. H. Eur. J. Org. Chem. 2005, 1777. (b) Kim, S. S. Pure. Appl. Chem. 2006, 78, 977.

[58] Zeng, Z.; Zhao, G.; Zhou, Z.; Tang, C. Eur. J. Org. Chem. 2008, 1615.

[59] North, M.; Williamson, C. Tetrahedron Lett. 2009, 50, 3249.

[60] North, M.; Stewart, E. L.; Young, C. Tetrahedron: Asymmetry 2012, 23, 1218.

[61] (a) Hamashima, Y.; Sawada, D.; Kanai, M.; Shibasaki, M. J. Am. Chem. Soc. 1999, 121, 2641.

(b) Hamashima, Y.; Sawada, D.; Nogami, H.; Kanai, M.; Shibasaki, M. Tetrahedron 2001, 57, 805.

[62] Hamashima, Y.; Sawada, D.; Nogami, H.; Kanai, M.; Shibasaki, M. Tetrahedron 2001, 57, 805.

[63] (a) Casas, J.; Nájera, C.; Sansano, J. M.; Saá, J. M. Org. Lett. 2002, 4, 2589.

(b) Casas, J.; Nájera, C.; Sansano, J. M.; Saá, J. M. Tetrahedron 2004, 60, 10487.

(c) Casas, J.; Baeza, A.; Sansano, J. M.; Nájera, C.; Saá, J. M. Tetrahedron Asymmetry 2003, 14, 197.

(d) Baeza, A.; Casas, J.; Nájera, C.; Sansano, J. M.; Saá, J. M. Eur. J. Org. Chem. 2006, 1949.

[64] (a) Qin, Y. C.; Liu, L.; Pu, L. Org. Lett. 2005, 7, 2381.

(b) Qin, Y. C.; Liu, L.; Pu, L.; Sabat, M. Tetrahedron 2006, 62, 9335.

[65] Iovel, I.; Popelis, Y.; Fleisher, M.; Lukevics, E. Tetrahedron: Asymmetry 1997, 8, 1279.

[66] Trost, B. M.; Martínez, S. Synlett 2005, 627.

[67] Kanai, M.; Hamashima, Y.; Shibasaki, M. Tetrahedron. Lett. 2000, 41, 2405.

[68] Lv, C. W.; Miao, C. X.; Xu, D. Q.; Wang, S. F.; Xia, C. G.; Sun, W. Catal. Commun. 2012, 27, 138.

[69] Holmes, I. P.; Kagan, H. B. Tetrahedron Lett. 2000, 41, 7453.

[70] Akagawa, K.; Kudo, K. Tetrahedron Lett. 2012, 53, 5981.

[71] Mo, K.; Yang, Y. H.; Cui, Y. J. Am. Chem. Soc. 2014, 136, 1746.

[72] Ryu, D. H.; Corey, E. J. J. Am. Chem. Soc. 2005, 127, 5384.

[73] (a) Choi, M. C. K.; Chan, S. S.; Matsumoto, K. Tetrahedron Lett. 1997, 38, 6669.

(b) Choi, M. C. K.; Chan, S. S.; Chan, M. K.; Kim, J. C.; Iida, H.; Matsumoto, K. Heterocycles 2004, 62, 643.

[74] Belokon, Y. N.; Green, B.; Ikonnikov, N. S.; North, M.; Tararov, V. I. Tetrahedron Lett. 1999, 40, 8147 .

[75] Hamashima, Y.; Kanai, M.; Shibasaki, M. J. Am. Chem. Soc. 2000, 122,7412

[76] (a) Shen, Y.; Feng, X.; Zhang, G.; Jiang, Y. Synlett 2002, 1353.

(b) Shen, Y.; Feng, X.; Li, Y.; Zhang, G.; Jiang, Y. Eur. J. Org. Chem. 2004, 129.

[77] (a) Chen, F. X.; Feng, X.; Qin, B.; Zhang, G.; Jiang, Y. Org. Lett. 2003, 5, 949 . 
(b) Chen, F. X.; Qin, B.; Feng, X.; Zhang, G.; Jiang, Y. Tetrahedron 2004, 60, 10449.

[78] Rajagopal, G.; Selvaraj, S.; Dhahagani, K. Tetrahedron: Asymmetry 2010, 21, 2265.

[79] Deng, H.; Isler, M. P.; Snapper, M. L.; Hoveyda, A. H. Angew. Chem., Int. Ed. 2002, 41, 1009.

[80] Chen, F. X.; Zhou, F.; Liu, X.; Qin, B.; Feng, X.; Zhang, G.; Jiang,
Y. Chem. Eur. J. 2004, 10, 4790.

[81] Kim, S. S.; Kwak, J. M. Tetrahedron 2006, 62, 49.

[82] Kim, S. S.; Lee, S. H.; Kwak, J. M. Tetrahedron: Asymmetry 2006, 17,1165 .

[83] Khan, H.; Agrawal, S.; Kureshy, R.; Abdi, S. R.; Jeyaprathap, K.; Jasra, R. Chirality 2009, 21, 262.

(Qin, X.) 